Vol. LXVI 2015

\title{
THE CONTRIBUTIONS TO THE STUDY OF CARBON MONOXIDE POLLUTION DUE TO CAR TRAFFIC IN A DENSELY POPULATED AREA
}

\author{
SORIN Borza \\ Professor, Ph.D, Engineering Faculty, “Lucian Blaga” University, Sibiu, Romania email: \\ sorin.borza@gmail.com
}

\begin{abstract}
Air quality monitoring is the most important environmental factor to be considered because it is the fastest way that helps pollutant transport into the environment. The development of human society has led to a negative anthropogenic and technogenic impact on air quality, resulting into a significant series of adverse effects on human health, flora, fauna and ecosystems in general. In this paper it is presentd the research work performed to monitor carbon monoxide emissions from motor vehicles in traffic, in a densely populated area in Sibiu. Also, in the paper it is described, the research findings conducted in accordance with national and European legislation. In our research we used GIS software, Geomedia Professional.
\end{abstract}

Key words: pollution, transportation, map, geographical information system, software

\section{Introduction}

Air quality monitoring is the most important environmental factor to be taken into account because it is the fastest way that helps pollutant transport into the environment. The development of human society has led to a negative anthropic and technogenic impact upon air quality, resulting into a significant series of adverse effects on human health, flora, fauna and ecosystems in general, [1].

The first goal of this paper is to present the research carried out to highlight the real value of carbon dioxide emissions taking into consideration European Union's legislation. The area chosen to conduct the research study represents the main arterial road where traffic peak hours exceed maximum admissible concentrations of air quality which directly influence the population's state of health.

Another goal of this paper is to present the research undertaken for carbon monxide mapping according to European Commission's requirements in order to obtain a overview on CO pollution produced by traffic in a well-marked area from Centre of Sibiu.

The map of carbon monoxide pollution was designed using the geographic IT software GeoMedia Professional, platform which helped the information distributed spatially to be created, stored and analysed and the processing of data collected by means of sonometer, [2]

According to information received from the Regional Environmental Protection Agency Sibiu, approaches to strategic CO mapping of Sibiu County have only recently started, and an auction for a competent company to obtain the rights to design the map is to be held at present.

\section{Legislative Regulations Regarding Air Quality}

Air is the environmental factor which represents the fastest support which favors pollutant transport in the environment. Air pollution has many and significant adverse effects on the population's health and may cause harm to flora and fauna in general, [8].

That is why special attention is given to the activity of air quality supervision and improvement. Air quality is determined both by air emissions coming from the static and mobile sources (traffic), mostly in major cities, and long distance pollutant transport, [8].

Romania is a member of the European Union (UE) and thus it harmonizes national legislation with that of EU. Air pollutants come from a large variety of mobile and static sources. In the EU legislation there are three categories of law:

1. Regarding air quality evaluation and management in general and that regarding the emissions coming from mobile sources. 
2. Regarding the emissions coming from static sources related to industrial installations and those of energy production.

3. Regarding emissions coming from incinerators [8].

This harmonization process involves European Directives in the field of environmental protection and air quality, including Framework Directive no. 96/62/CE from 27 September 1996 regarding the evaluation and management of ambient air quality, directive known under the name „Air Quality Framework Directive" [8].

Romania became a member of the European Environmental Agency (EEA) in 2002 and is expected to provide data regarding environment quality.

The monitorized pollutants, measuring methods, limit values, alert and information thresholds and the criteria for setting monitoring points are established by the national legislation regarding atmosphere protection according to the requirements stipulated in the European regulations [8].

Council Directive no. 96/62/CE and the daughter directives (Council Directive no.1999/30/CE regarding limit values for $\mathrm{SO}$, nitric dioxide and nitric oxides, suspended particles and $\mathrm{Pb}$ in atmospheric air, Council Directive no. 2000/69/CE regarding benzene and carbon monoxide in the environmental air and Council Directive no. 2002/3/CE regarding air pollution with ozone) are already transferred into Romanian legislation. This thing was achieved by Environmental Ministry Decree no.592/2002.

\section{Air quality evaluation and management}

In densely populated urban areas where, as a result of air quality evaluation, one can notice that the concentration values in the environment exceed limit value or/and alert threshold, territorial public authority for environmental protection initiates the elaboration of the air quality management plan/program [6].

The territorial public authority for environmental protection informs and warns public administration authorities in case a source which generated the pollution episode is a mobile one [6].

The territorial public authority for environmental protection collaborates with public administration authorities to elaborate the air quality management plan/programme, [6].

The Framework Directive for Air Quality was followed by the so-called „DAUGHTER directives" which establish the numerical limit values and the target values for each of the identified pollutants. Despite setting air quality limits and alert thresholds, the objectives of the daughter directives are to harmonize monitoring strategies, measuring and calibration methods, and air quality assessment methods to obtain measures comparable to those in EU and ensure a complete information of the public. The development of daughter legislation is supported by working groups made up of experts for the preparation of their position document which the Comission uses as basis for the drafting of the legislation [6].

The Framework Directive and the Daughter Directives require air quality assessment from member states based on mutual methods and criteria.

The first Daughter Directive (1990/30/EC) concerning the limit values for NOx, SO2, Pb and PM10 in air came into effect in July 1999. Member states had two years to implement the directive and establish the monitoring strategies, as well as to ensure that the public receives the latest information regarding the concentrations of NOx, SO2, particles and lead. The limit values of NOx for vegetation protection must be achieved by 2001. The limit values of SO2 and PM10 must be achieved by 2005. The other limit values of NO2 and $\mathrm{Pb}$ must be achieved by 2010. Member states must prepare the conformance programs showing how limit values must be achieved in time for those areas where the conformance cannot be accomplished through „traditional business”. These programs must be directly made available to the public and they must also be sent to the European Commission [6].

One of the most important environmental standards was air quality standard which stipulates the maximum admissible concentrations of some important pollutants within a certain time period in protected areas - STAS 12574 - 87, which is partially replaced by Decree MAPM no. 592 from 25.06.2002 for the approval of the Normative Document concerning limit values, threshold values and evaluation criteria and methods of SO2, NO2 and nitrogen oxides, suspended powder (PM10 and PM2,5), lead, benzene, $\mathrm{CO}$ and the ozone in atmospheric air [6].

At ambient environment temperature, carbon monoxide is a colourless, odorless, insipid gas, both of natural and anthropic origin. Carbon monoxide is mainly the result of the incomplete combustion of fossil fuels, [7]:

- $\quad$ Natural sources: forest combustion, volcanic emissions, and lightning.

- $\quad$ Anthropic sources: they are mainly the result of of the incomplete combustion of fossil fuels. 
Other anthropic sources: steel and iron production, oil refinement, road, air and railway traffic. Carbon monoxide can accumulate to a dangerous level especially during the atmospheric calmness

in winter and spring (it is more stable from a chemical point of view at low temperatures), when fossil fuels achieve a maximum. Carbon monoxide produced from natural sources is very quickly scattered on a smooth surface, which does not threaten human health, [3].

Carbon monoxide is a toxic gas, which is lethal in large concentrations (for concentrations of approximately $100 \mathrm{mg} / \mathrm{m} 3$ ) by reducing the capacity of oxygen transport in the blood, with consequences on the respiratory and cardiovascular systems.

In relatively low concentrations, carbon monoxide:

- $\quad$ Affects central nervous system;

- $\quad$ Lowers blood pressure, thus reducing blood volume distributed in organism;

- $\quad$ Reduces visual acuity and physical capacity;

- $\quad$ Short-term exposure can cause acute tiredness;

- $\quad$ Can cause respiratory difficulties and chest pain to persons with cardiovascular diseases;

- Determines iritability, migraines, fast respiration, lack of coordination, nausea, dizziness, bewilderment, and reduces capacity to concentrate, [4].

Children, old people, persons with respiratory and cardiovascular diseases, anemic persons and smokers represent the segment of population which is the most affected by exposure to carbon monoxide, [3].

Effects on plants: in concentrations usually monitored in atmosphere, it does no have effects on plants, animals and environment.

The landmark method for the measurement of carbon monoxide is stipulated in the SR EN 14626 standard Environmental air quality. The standardised method for the measurement of carbon monoxide concentration by spectroscopy in non-dispersive infrared, [9].

There should be at least 3 specific parameters available corresponding to monitored pollutants for the general parameter to be calculated. The general parameter and the specific ones are integers ranging from 1 to 6, each number corresponding to a colour (figure 2 represents colours as well as numbers associated to them), [5].

Figure 1 Colour code for air quality parameters

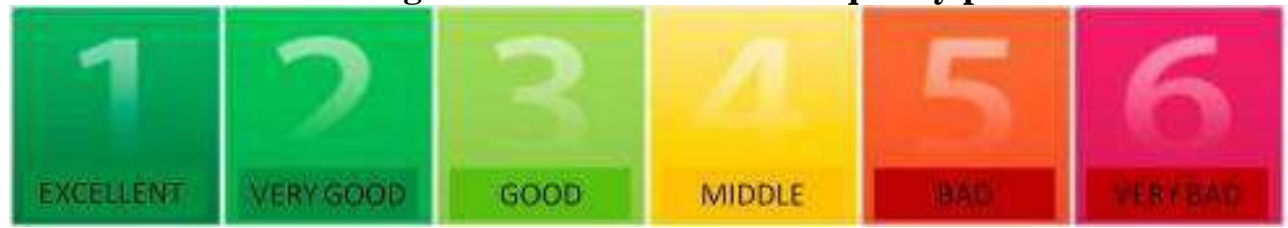

The specific parameter corresponding to carbon monoxide is determined by fitting the arithmetic average of hourly values, recorded in the last 8 hours, in one of concentration fields recorded in table 1 . as follows, [10]:

Table 1 Specific parameter for CO concentrations

\begin{tabular}{|c|c|}
\hline $\begin{array}{c}\text { Domeniu de concentrații pentru CO } \\
\left(\mathrm{mg} / \mathrm{m}^{3}\right)\end{array}$ & Indice specific \\
\hline $0-2$ & 1 \\
\hline $3-4$ & 2 \\
\hline $5-6$ & 3 \\
\hline $7-9$ & 4 \\
\hline $10-14$ & 5 \\
\hline$>15$ & 6 \\
\hline
\end{tabular}




\section{Performed Measurements}

Measurements were performed in a period of time between 06:00 and 18:00 o'clock. On the day measurements were taken, air minimum temperature was $11^{\circ} \mathrm{C}$ and maximum one was $26^{\circ} \mathrm{C}$. Wind speed was 2 meters/second ( $8 \mathrm{~km} /$ hour). Due to relatively low wind speed, pollutant dispersion was not good. Measurements were performed at human respiration level, in the areas exclusively for pedestrian circulation.

Measurement results are presented in table 2

Table 2. Measurement results

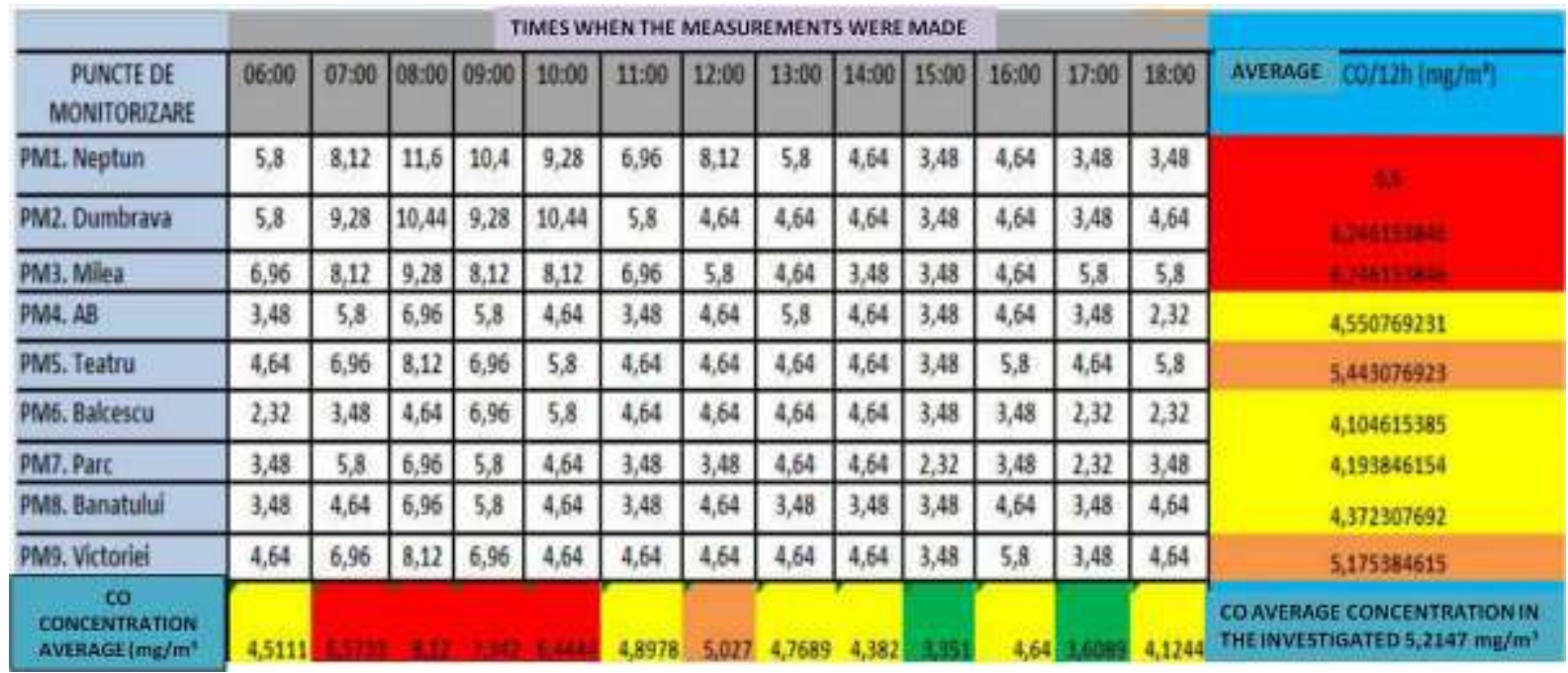

The evolution of concentrations in the area studied is presented in figure 2

Figure 2 CO Pollution evolution in monitored points

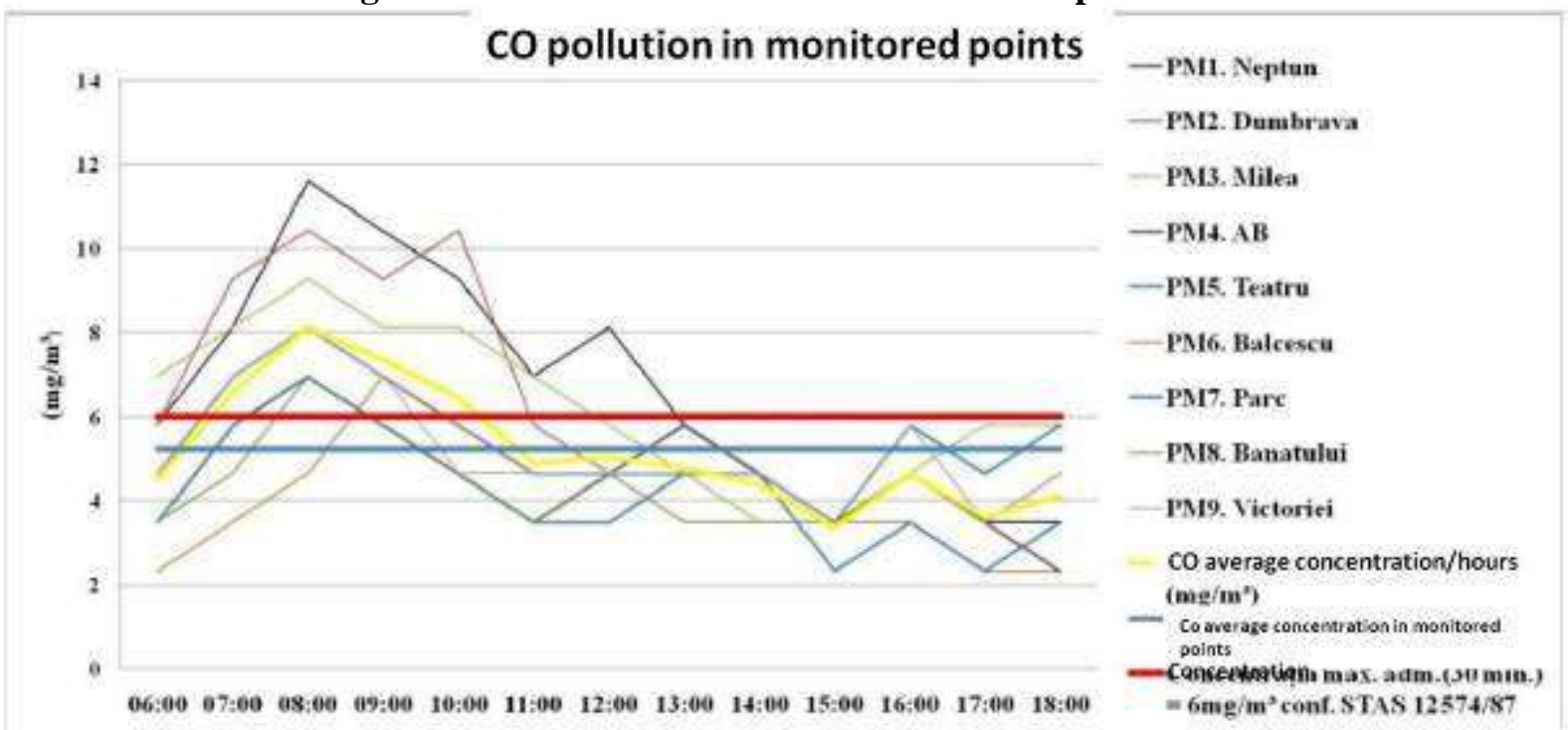

\section{Using GIS to Analyse Data Regarding Research Performed for the Monitoring of Carbon Monoxide, due to Motor Vehicle Traffic}

In this chapter of the paper we shall present spatial analysis performed on research regarding pollution with carbon monoxide, as well as noise mapping regarding noise pollution produced by motor vehicles. 


\subsection{Collected Data Spatial Analysis for Carbon Monoxide Pollution Research}

For air quality monitoring study and research regarding carbon monoxide pollution, measurements were taken in nine points strategically located. These monitoring points were called "MP", for example "MP1.Neptun” (figure 3).

Figura 3 The Points where measurements were taken to determine carbon monoxide concentration

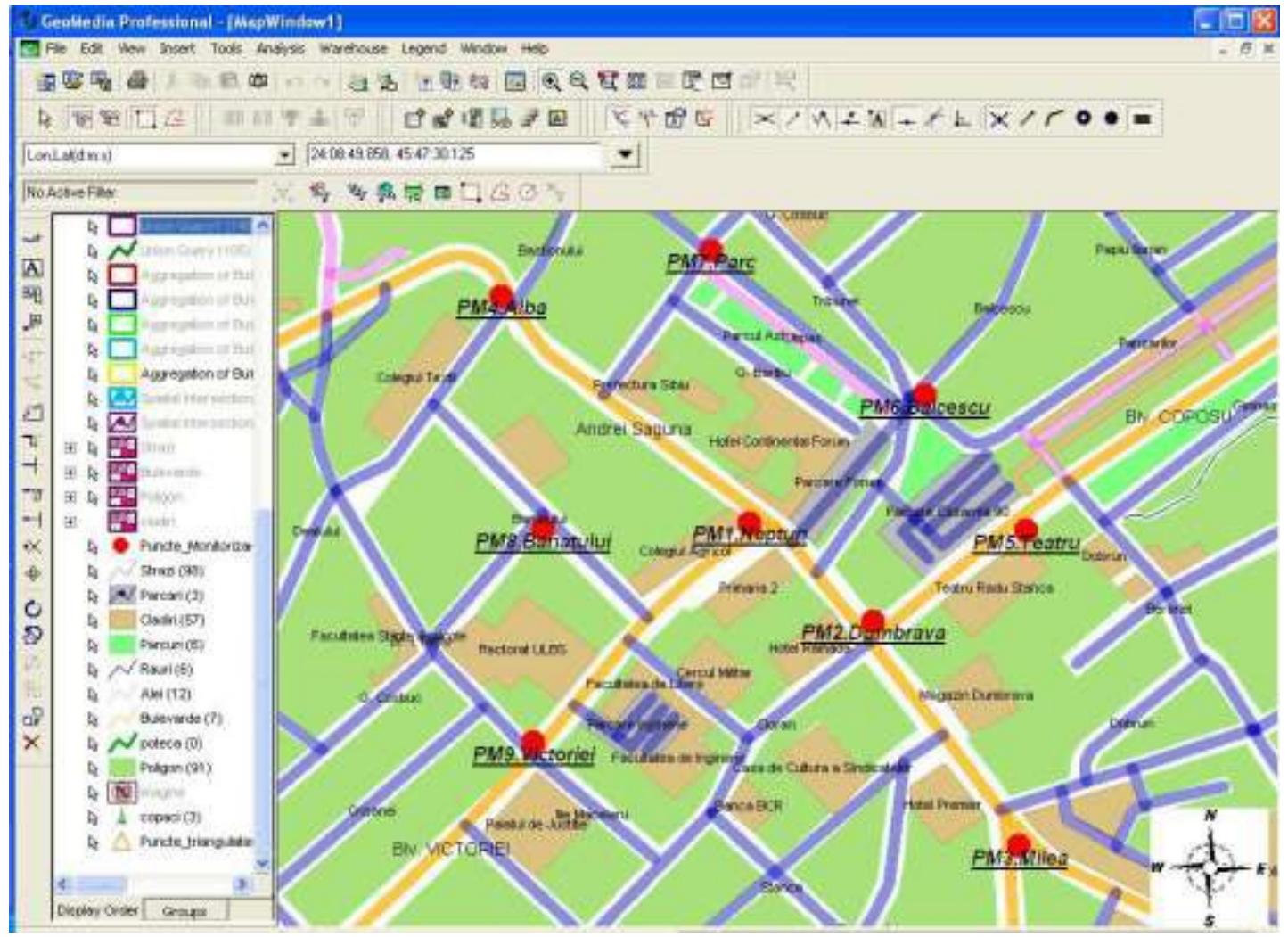

The spatial analysis which was performed highlighted the points which exceed admissible maximum concentration stipulated in STAS $12574 / 87$ (30 minute) $=6 \mathrm{mg} / \mathrm{m}^{3}$ at certain time intervals. Figure 4 presents the points where $\mathrm{CO}$ concentration is exceeded at 8 o'clock.

Figure 4 Points where CO concentration is exceeded at 8 o'clock.

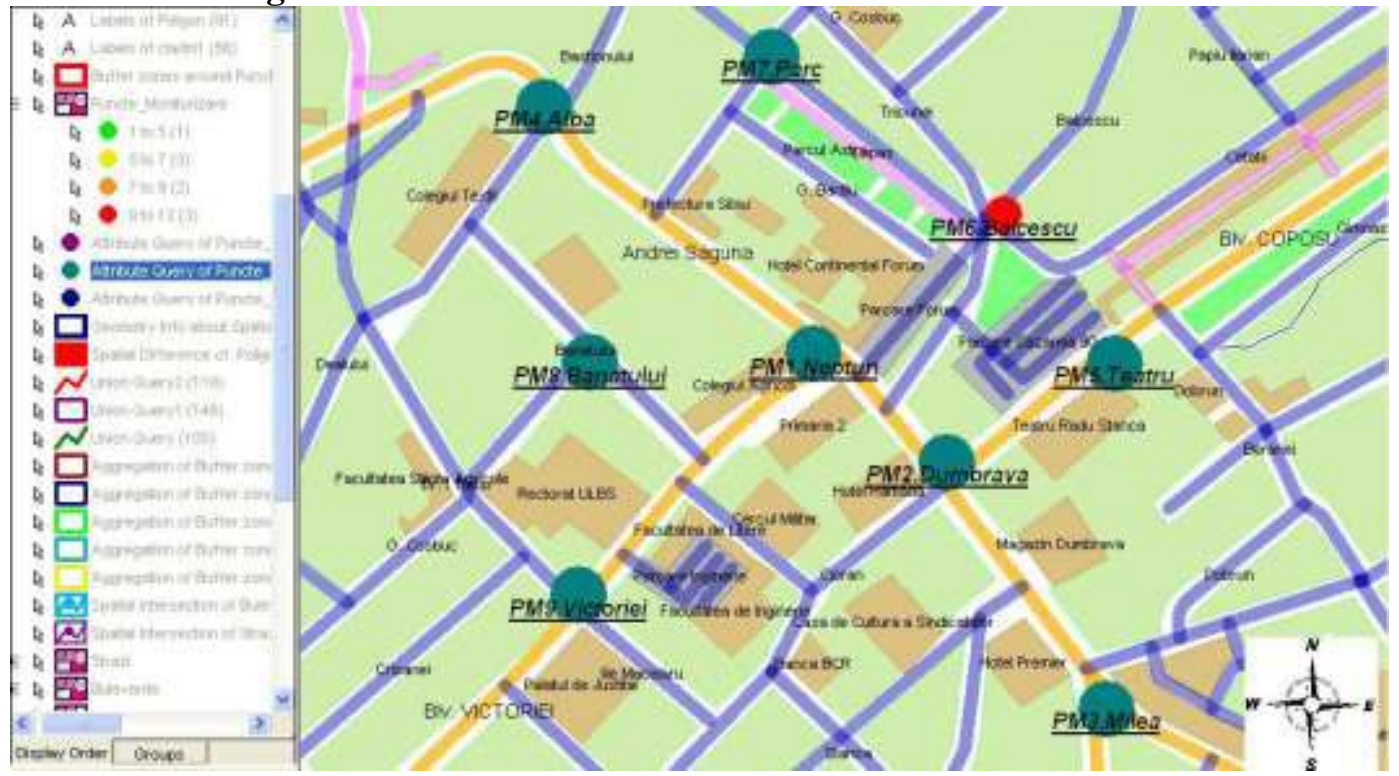


The use of GIS software, Geomedia Professional, permitted a detailed analysis of field data, and thus pollution maps were obtained for certain time intervals, using instruments which it provides. The spatial interrogations permitted synthetical calculations in the area under research.

\section{Conclusions}

Based on the present documentation an integrated system for air quality monitoring regarding the concentrations of CO emissions, were designed and developed. The integrated system for pollution analysis and research functions in the following way:

4. The device measures and records carbon monoxide concentrations;

5. The virtual device performs calculations, makes graphics regarding $\mathrm{CO}$ and noise exceedings and stores data in an Access database;

6. The data stored are then used for the attributes of the elements and objects which can be found in the maps developed with GeoMedia Professional software;

7. Based on the element attributes the maps and elements specific to necessary spatial analyses are developed automatically to perform interrogations such as Atribute Querry, Buffer Zone, Aggregation etc.

Developing this system for data monitoring and analysis, allows for a reduction of the human factor as much as possible in data processing and generation in ,intelligent maps” GIS. As a result of the analysis, it was concluded that between 08:00 and 12:00 o'clock, air quality regarding carbon monoxide emissions in the area under research, exceed admissible maximum concentrations stipulated in STAS $12574 / 87$.

Data spatial analysis allows an instantaneous determination of the exceedings of pollution regulations stipulated by the legislation in effect.

Data spatial analysis allowed a precise determination of the exceedings of hourly and daily pollution regulations.

Developing „Intelligent maps” with points where air quality measurements were taken helps important decisions to be made concerning human factor protection and environmental protection.

\section{References}

- Arghir M., Ispas V, Stoian I, Blaga F, Borzan C., Ecologia Transportului de suprafață în aglomerările urbane", EDP, București, pag.76, (2008);

- Borza S, "Introducere în GeoMedia" Editura Universității Lucian Blaga, Sibiu, (2008);

- King E A, Murphy E, Rice H J, , "Evaluating the impact on noise levels of ban on private cars in Dublin city center, Ireland”, Journal of Transportation Research, Dublin, Vol. 16, pag. 532-539, (2011);

- Kumar R, ” Assessment of traffic noise and its impact on certain personnel” Indian Journal of Otolaryngology and Head \& Neck Survey , Madras Medical College, Chennai, Vol.49, pag. 4750, (1997);

- Lengagne $\mathrm{T}$, "Traffic noise effects communication behaviour in a breeding anuran, Hyla arborea”, Journal of Biological Conservation, Lyon, Vol. 141, pag. 2023-2031, (2008);

- Macoveanu, M., Politici si strategii de mediu”, Ed. Ecozone, Iasi, (2006);

- Majumder A K, Murthy V K, , "Spatial and Temporal Variation of Ambient PM: A case study of Banepa Valley, Nepal”, Journal of Science, Engineering and Technology, Nepal, Vol. 8, No.1, pag. 23-32, (2012);

- Zaharia C., Legislatia privind protectia mediului”, Ed. Politehnium, Iasi, pag. 140, 2008;

- $\quad$ www.mmediu.ro

- $\quad$ www.calitateaer.ro 